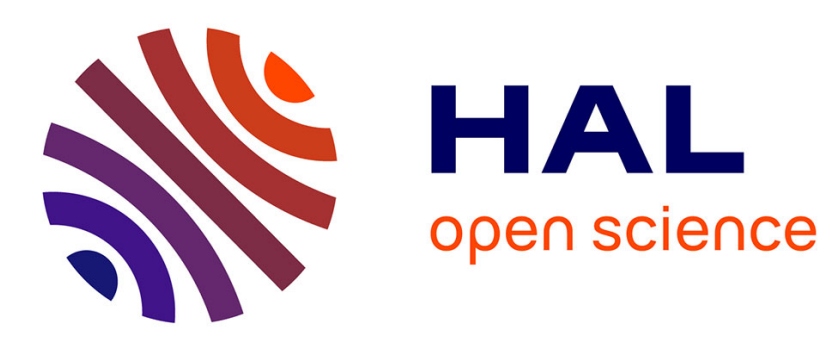

\title{
Simulating calculations and optimization design of a new HVDC supply power for light rail system
}

Rémi Vial, Delphine Riu, Nicolas Retière

\section{To cite this version:}

Rémi Vial, Delphine Riu, Nicolas Retière. Simulating calculations and optimization design of a new HVDC supply power for light rail system. IECON 2010, Nov 2010, Phoenix, United States. hal00545081

\section{HAL Id: hal-00545081 \\ https://hal.science/hal-00545081}

Submitted on 9 Dec 2010

HAL is a multi-disciplinary open access archive for the deposit and dissemination of scientific research documents, whether they are published or not. The documents may come from teaching and research institutions in France or abroad, or from public or private research centers.
L'archive ouverte pluridisciplinaire HAL, est destinée au dépôt et à la diffusion de documents scientifiques de niveau recherche, publiés ou non, émanant des établissements d'enseignement et de recherche français ou étrangers, des laboratoires publics ou privés. 


\title{
Simulating calculations and optimization design of a new HVDC supply power for light rail system
}

\author{
Rémi Vial, Delphine Riu, Nicolas Retière \\ Grenoble Electrical Engineering Laboratory, 38402 Saint-Martin d'Hères, France \\ E-mail : \{remi.vial, delphine.riu, nicolas.retiere\}@g2elab.grenoble-inp.fr
}

\begin{abstract}
In this paper, a new HVDC power supply system for light rail systems is presented and compared to classical distribution networks based on $\mathrm{AC} / \mathrm{DC}$ controlled converters. A simulation tool has been developed to simulate such a complex system, taking into account vehicle motion and HVDC electrical distribution. Then, an optimization of HVDC structure and control will be presented using Lagrangian formulation. All the results are compared to classical distributions, and show the effectiveness of the proposed power supply distribution used for light rail systems.
\end{abstract}

Index terms- Light rail systems, HVDC power supply, simulating tool, optimization design.

\section{INTRODUCTION}

Public transportation systems are expected to reduce their energy consumption following the European energy saving policy. Transport system providers (Light Rail, Rapid Transit, High Speed Train) such as ALSTOM Company are aiming to offer energy-saving light rail system with low investments and operation costs [1].

A light rail system is a complex system including a moving electrical vehicle supply by overhead contact line. Nowadays, this kind of transportation system is largely used in urban area which suffocates under car traffic. Its construction is cheaper and requires less work than an underground light rail $[1,3]$.

Energy saving in a light rail power system can be realized by improving its energy efficiency with a better braking energy recovery by means of energy storage in vehicles, a consumption by nearby vehicles or a high efficiency distribution system. In this article, the authors have focused on this last point of improvement.

Classically, power supply in a light rail system is composed with megawatt bulk substations, which includes a power transformer, a rectifier with diodes and protections [2]. This kind of substation is uncontrollable and irreversible, which limits the possible improvement of efficiency of the global system. Moreover, their integration in urban area is difficult because of their volume [3].

This paper deals with an original power supply for light rail systems. Thus, the authors suggest a power topology which reduces losses and includes control architectures contrary to classical substations. This power architecture is based on the utilization of an intermediary high voltage feeder which links together rectifier and light substation distributed along the track. Light substations are simple synchronous buck converters HVDC to LVDC. These substations would then be costless and their integration could be easier. This topology reduces the number of traction supply substation (TSS) and allows a better standardization thus reducing the costs.

The first part of this article presents this new supply system based on HVDC substations. Then, a simulating tool of the global light rail system including mechanical and electrical systems is described. Thirdly, a comparison between classical and HVDC supply networks is presented on a simple vehicle path. Finally, some results of optimization are presented, showing the influence of control on global performances of the system.

\section{STUDIED POWER SYSTEM}

\section{A. Classical supply network}

Usually, light rail consumes a peak power of one megawatt. It is fed by an overhead line from the TSS in $750 \mathrm{~V}$ DC. The voltage of this overhead line must stay between $600 \mathrm{~V}$ and $900 \mathrm{~V}$ to allow a normal operation of the rolling stock. TSSs are consequently disposed along the track at each kilometer to keep voltage in this operating range [2].

In a standard TSS, $20 \mathrm{kV}$ AC power from the distribution network is stepped down by a transformer to $585 \mathrm{~V}$ AC and rectified to supply the network (see Fig. 1). There are different technologies of rectifiers in light rail systems, but three-phase diode bridge remains mainly used [3]. DC current at $790 \mathrm{~V}$ flows through a breaker before feeding the overhead contact line. Finally, input filters are often required to decrease harmonic pollutions generated by the rectifier on distribution networks [2,4].

Concerning the vehicle components, the supplied current feeds a dc bus through a pantograph and a LC input filter. Then, the engine is composed of inverters supplying asynchronous traction motors [3], whose torque is controlled by drivers and embedded computers to reach time schedule and to ensure a comfortable operation.

This classical network is mainly used but leads to two main problems. First, diode bridges are not reversible, then current 
can flow only in one direction, from AC supply network to vehicle.

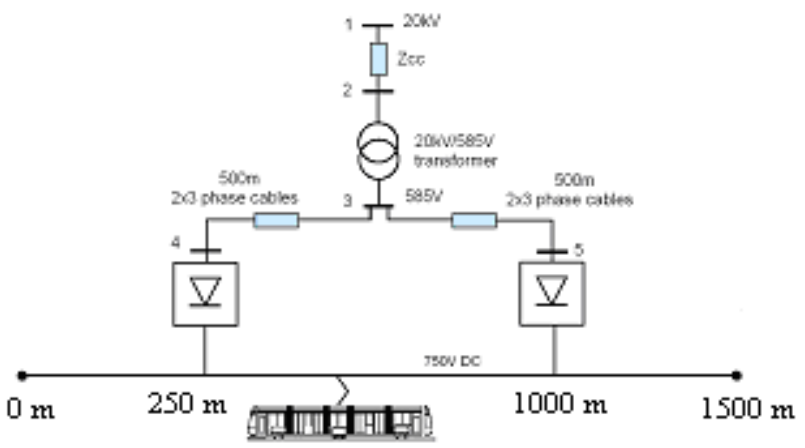

Fig. 1.Standard supply system

When a vehicle slows down, traction motors work as generators and inverters as rectifiers. Consequently, power is sent back on contact line and, if another vehicle in traction phase is not sufficiently near, voltage level of the DC bus reaches $900 \mathrm{~V}$. Therefore, a rheostat is turned on to absorb excess power, which leads to decrease efficiency [12].

Secondly, TSSs are large and expensive. Their integration in downtown is quite difficult and usually, their positions are not only guided by electrical considerations. Then, voltage drops or increases could be more and more critical with the distance between vehicle and TSS.

These two issues increase losses and reduce regenerative breaking potential $[3,12]$.

\section{B. HVDC supply network}

HVDC networks are more and more used today thanks to progress in power electronics. They are present in national power grids as well as in data centers or wind farms $[5,6]$. The power supply network proposed in this paper is based on an intermediary HVDC bus between TSS and overhead contact line. Indeed, the reduction of losses in power supplies can be commonly realized using higher voltages. High speed trains in France for instance are fed by a $25 \mathrm{kV}$ AC contact line, with a feeder at $25 \mathrm{kV}$ along the track which allows power transport at $50 \mathrm{kV}$. Voltage is then stepped down by autotransformers regularly spaced between TSS.

In this article, the authors propose a new HVDC power supply based on the same principle. However, instead of using transformers to step down voltage from intermediary HVDC feeders, synchronous buck converters are introduced (see Fig. 2). Buck converters are the simplest power converters, who work with only two power switches and filters, are power reversible and fully controllable.

It is then possible to use it to keep voltage level into templates and to control power flow in the network. By simply adjusting its duty cycle, the whole system can be controlled with a better efficiency. Energy exchanges between vehicles are simplified, allowing removal of braking rheostat and less exchange with the grid. Moreover, buck converters are cheaper and smaller than TSS. Their integration will be facilitated and they can be placed at strategic locations.

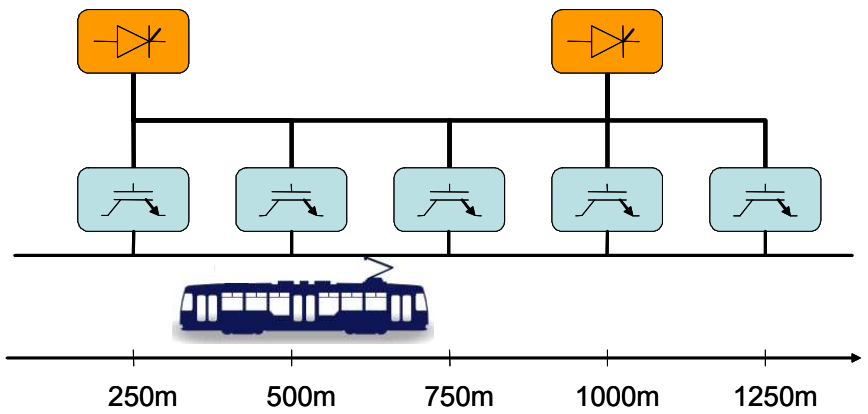

Fig. 2. HVDC supply system

\section{Studied light rail path}

The path is described on Fig. 1 and 2. The line measures $1.5 \mathrm{~km}$, with regularly spaced stations and substations. The vehicle has an assigned power of $1 \mathrm{MW}$.

\section{MODELING OF HVDC LIGHT RAIL SYSTEM FOR SIMULATION TOOL}

Light rail systems are therefore complex systems to design with vehicles in motion, numerous power electronics converters and several performances to achieve. There are many simulation tools but, they are classically constructed for AC/DC power supply systems modeling, for mechanical behavior description of vehicle and/or, more rarely, for design of light rail systems $[8,9,10,12]$. Obviously, they are not adapted for our power supply topology.

Then, the authors have developed a simulation tool on Matlab $^{\mathcal{C}}$, dedicated to static modeling of HVDC light rail systems. This simulator is divided into three parts. First part simulates mechanical behavior of vehicles. The second models the behavior of the driver and finally, the last part is a mixed AC/DC power flow.

In this part, we are interested in component modeling as vehicle motion and torque on the first hand, and, on the other hand, electrical power systems. Then, calculation performances and results from simulation tool will be presented and discussed.

\section{A. $\quad$ Vehicle motion modeling}

The maximal torque of traction motors in motoring and breaking regions depends on speed and bus voltage. It can be expressed as [7] : 


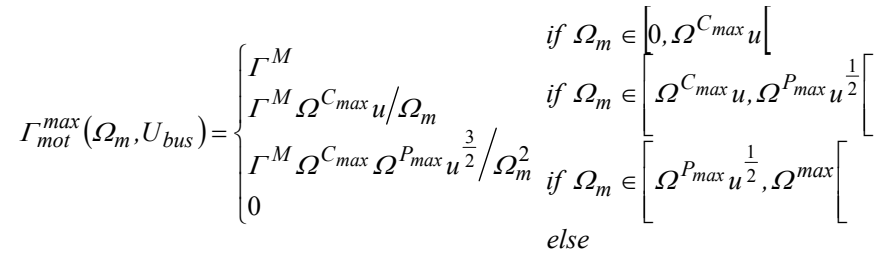

where $\Gamma_{m o t}^{\max }$ is the maximal motor torque for the motor speed $\Omega_{m}$, at the bus voltage $U_{b u s} . \Gamma^{M}, \Omega^{C_{\max }}, \Omega^{P_{\max }}$ are constant for the consider motor. $u$ is a rating factor defined by (1).

$$
\mathrm{u}=\min \left(\mathrm{U}_{\text {bus }} / \mathrm{U}_{\text {bus_nom }}, 1\right)
$$

where $U_{\text {bus_nom }}$, is the nominal voltage of dc bus.

Fig. 3 shows the variation of torque vs mechanical speed for several DC voltages obtained from (1).

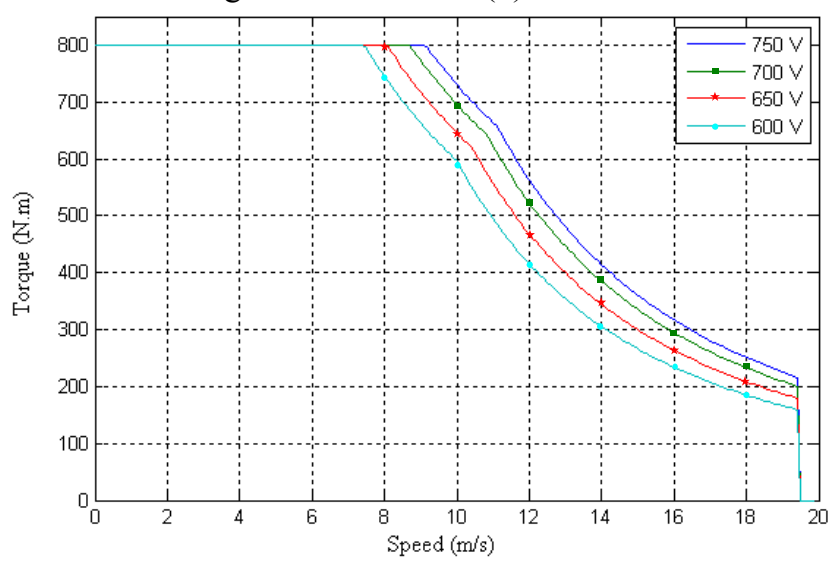

Fig. 3. Vehicle motion modeling

This maximal torque is then modulated by the driver to reach his objective. It can be expressed by (2) $[3,7]$.

$$
\Gamma_{\text {mot }}\left(\Omega_{m}, U_{\text {bus }}, \gamma\right)= \begin{cases}\gamma \cdot \Gamma_{\text {mot }}^{M \max }\left(\Omega_{m}, U_{\text {bus }}\right) & \text { if } \gamma>0 \\ 0 & \text { if } \gamma=0 \\ \gamma \cdot \Gamma_{\text {mot }}^{\text {Bmax }}\left(\Omega_{m}, U_{\text {bus }}\right) & \text { if } \gamma<0\end{cases}
$$

where $\gamma \in[-1,1]$ is called notch command. This parameter is introduced to model the driver behavior regarding traction or braking needs.

The motor stress is then deduced taking into account reduction gear and wheels. This stress generated by the whole vehicle can be given by (3):

$$
F_{m o t}\left(v, U_{\text {bus }}, \gamma\right)=\frac{n_{m o t} \eta}{r k_{g}} \Gamma_{m}\left(v / r k_{g}, U_{\text {bus }}\right)
$$

where $F_{m}$ is the motion stress developed by the entire vehicle for the speed $v . n_{m o t}$ is the number of motors, $\eta$ their efficiency (taking into account the gear box), $k_{g}$ is the ratio of gear box and $r$, the radius of a wheel.

Acceleration can now be easily computed after subtracting friction stresses and grade resistances (4).

$$
\begin{gathered}
F_{f}=A+B v+C v^{2}+m g \sin (i) \\
m \xi \frac{d v}{d t}=F_{m o t}-F_{f}
\end{gathered}
$$

where $i$ is the inclination of the track, $\mathrm{m}$, the mass of vehicle ,$\xi$, a coefficient which takes into account rotational inertia and $\mathrm{A}, \mathrm{B}$ and $\mathrm{C}$ remain constant.

By successive integrations, it is then possible to compute velocity and position of the vehicle.

All these variables are monitored by an embedded computer and limited to keep sufficient adherence and comfortable driving. Then, jerk effect and acceleration must be bound [7].

This model allows computing all mechanical variables, from track profile and driver behavior. It should be noted that driver behavior is a difficult part of modeling procedure [6, 11]. In our case, the driver is more than a simple controller; he has also to anticipate speed limitations and stops. By calculating the stopping or braking distance for each computation point, the authors are able to know if the driver must accelerate, brake or coast.

Finally, Fig. 4 shows the electrical power required to supply the vehicle on a simple path from mechanical calculations. This curve is calculated for a fixed voltage value of the DC bus, $\mathrm{U}_{\text {bus. }}$. By the way, this voltage is able to more fluctuate on a standard path. The electrical power modeling is then necessary to improve analysis.

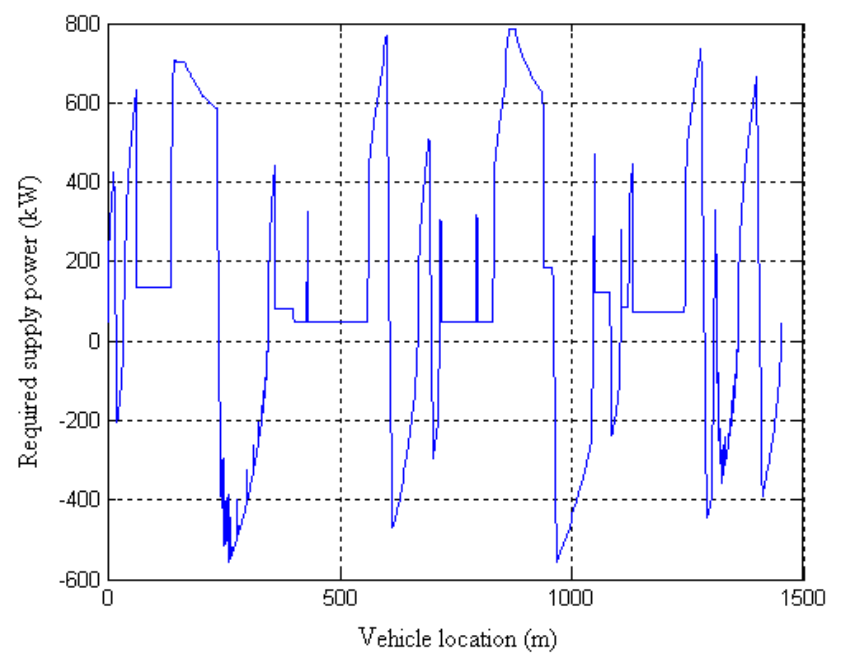

Fig. 4. Required supply power vs vehicle location 


\section{B. Electrical supply system modeling}

Then, the last part of static modeling consists in a power flow of the HVDC supply systems. First, all electrical dynamics are neglected. With this hypothesis, AC/DC rectifier could be described simply by a voltage source with series resistor (6) which takes part of overlaps.

$$
V_{r}=\frac{3 \sqrt{2}}{\pi} U_{A C} \cos \alpha_{r}-\frac{3 X_{c}}{\pi} I_{d}
$$

$V_{r}$ is the average rectifier DC output voltage, $U_{a c}$ the AC voltage magnitude, $\cos \alpha$, the pre-ignition angle (for thyristor rectifier only), $X_{c}$, the rectifier transformer reactance and $I_{d}$, the rectifier DC current [12].

Power flows resolution is based on Newton-Raphson algorithm and it is convenient to work with per units [13]. Equation (6) can be rewrite as in (7) in per units system.

$$
V_{r}=U_{A C} \cos \alpha_{r}-\frac{\pi}{6} X_{c} I_{r}
$$

Active and reactive powers of a three-phase rectifier are then expressed by (8):

$$
\begin{gathered}
P_{r}=V_{d} I_{d} \\
Q_{r}=V_{d} I_{d} \tan \varphi
\end{gathered}
$$

where power factor is computed with (9) :

$$
\tan \varphi=\frac{k U_{A C}}{V_{d}} \sqrt{1-\left(\frac{V_{d}}{k U_{A C}}\right)^{2}}
$$

where $k$ can be considered as a constant near unity.

HVDC part of network is described by a constant conductance matrix which links rectifier variables with values of voltage and current buck converters on the high voltage side, respectively noted $V_{h v}$ and $I_{h v}$ :

$$
\left[\begin{array}{ll}
G_{11} & G_{12} \\
G_{21} & G_{22}
\end{array}\right]\left[\begin{array}{c}
V_{r} \\
V_{h v}
\end{array}\right]-\left[\begin{array}{c}
I_{r} \\
-I_{h v}
\end{array}\right]=0
$$

For the LVDC part of the network (overhead contact line), conductance matrix changes with vehicle position. Then, the structure of this matrix depends of interconnection between vehicle and buck converters. Moreover, coefficients change with the vehicle position, according to :

$$
\left[\begin{array}{ll}
H_{11} & H_{12} \\
H_{21} & H_{22}
\end{array}\right]\left[\begin{array}{c}
V_{l v} \\
V_{t}
\end{array}\right]-\left[\begin{array}{c}
I_{l v} \\
P_{t} / V_{t}
\end{array}\right]=0
$$

$V_{l v}$ and $I_{l v}$ are voltage and current on the low voltage side of buck converters. $\mathrm{V}_{\mathrm{t}}$ and $\mathrm{P}_{\mathrm{t}}$ are the vehicle voltage and electrical power, respectively.
Buck converters are modeled with DC equivalent transformers. Currents and voltages are simply modulated by the duty cycle between input and output (12) [14].

$$
\left\{\begin{array}{l}
I_{h v}-\alpha I_{l v}=0 \\
\alpha V_{h v}-V_{l v}=0
\end{array}\right.
$$

For the ac part, we find classical equation for power flow (13), which must be equal to $P_{r}$ and $Q_{r}$ for node where rectifiers are connected, and 0 elsewhere.

$$
\begin{aligned}
& P_{i}=U_{i} \sum_{k} U_{k}\left[G_{i k} \cos \left(\theta_{i}-\theta_{k}\right)+B_{i k} \sin \left(\theta_{i}-\theta_{k}\right)\right] \\
& Q_{i}=U_{i} \sum_{k} U_{k}\left[G_{i k} \sin \left(\theta_{i}-\theta_{k}\right)-B_{i k} \cos \left(\theta_{i}-\theta_{k}\right)\right]
\end{aligned}
$$

By solving this non linear system, it is possible to compute the efficiency for different structures and different control modes. As buck converters are fully controllable and reversible, it is necessary to chose right duty cycles to avoid current circulation which can create losses. Moreover, different converters can interact with each other and create low frequency interferences. Input filter of converter can also create instability and it is necessary to study dynamical behavior of electrical network. But this will be presented in further works.

\section{Simulating tool presentation}

This simulating tool has been developed on Matlab@ to analyze the global light rail system. First, the program calculates, for a given contact line voltage, the power supply required by the engine. Then, a power flow of HVDC power supply system is calculated, improving the value of the vehicle voltage. A new step of calculations is then calculated on vehicle side, and so on. For a simple path, the time simulation is about $4 \mathrm{sec}$ which is very reasonable.

\section{ANALYSIS OF HVDC STRUCTURE}

In this section, the classical and HVDC structures are compared according to efficiency and supply voltage of light rail system. More results will be presented in the following section with optimization of command strategies.

For a simple travel between first and last stations, Fig. 5 and 6 show the global efficiency and voltage calculated on the supply AC bus.

Then, from these time simulations, it is clear that this new structure of power supply based on DC/DC converters to allow significantly enhancement of global efficiency and the power quality of the distribution. These results are more obvious between substations, where the differences can reach 2 points on efficiency and $20 \mathrm{~V}$ on DC voltages. 


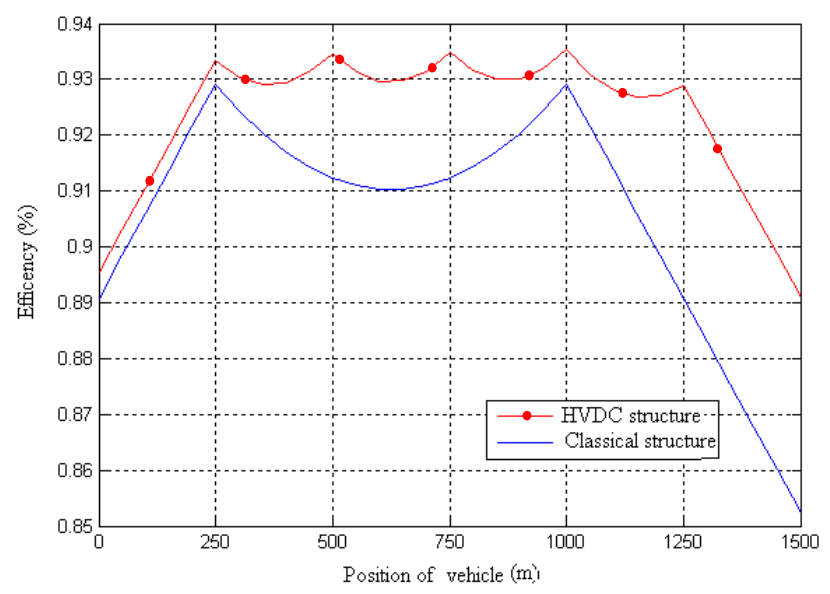

Fig. 5. Efficiency of presented supply systems

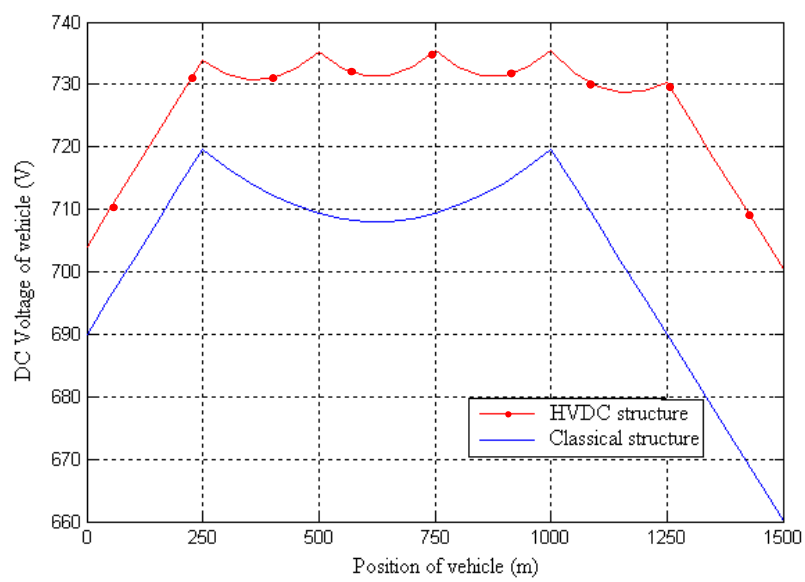

Fig. 6. DC Voltage of presented supply systems

Finally, this simulation tool allows light rail designers to evaluate global performances of a given power supply topology with a reasonable computing time. Moreover, this tool allows calculation of the energetic efficiency of a structure which can be interesting for structure with embedded storage, in order to design and optimize the power of power sources as substations and storage [11].

\section{OPTIMIZATION OF DESIGN}

In this last part, the authors have proposed a static optimization of the supply system. Then, the right control law to minimize losses in network with respect to electrical constraints is determined. Equality constraints come from (7) to (13); inequality constraints are derived from light rail standard on voltage levels (14) [14].

$$
V_{\text {min }} \leq\left[\begin{array}{c}
V_{l v} \\
V_{t}
\end{array}\right] \leq V_{\text {max }}
$$

The optimization problem can then be formulated as (15):

$$
\begin{array}{ll}
\text { Minimize } & f(x, u) \\
\text { Subject to }:\left\{\begin{array}{l}
g(x, u)=0 \\
h(x, u)<0
\end{array}\right.
\end{array}
$$

where $\mathrm{x}$ and $\mathrm{u}$ denote respectively electrical variable and control variable (ie rectifier preignition angle and duty ratio of buck converter) :

$$
\begin{gathered}
x=\left[\theta, U, \theta_{r}, U_{r}, V_{r}, I_{r}, V_{h v}, V_{l v}, I_{l v}, V_{t}\right]^{T} \\
u=\left[\cos \alpha_{r}, \alpha\right]^{T}
\end{gathered}
$$

Objective function, consisting in reducing power losses, is then defined as:

$$
f(x, u)=\sum P_{r}
$$

Finally, equality constraints of the problem can be described as:

$$
g=\left[\begin{array}{c}
P_{i}(\theta, U) \\
Q_{i}(\theta, U) \\
P_{i}(\theta, U)+V_{r} I_{r} \\
Q_{i}(\theta, U)+k I_{r} U_{r} \sqrt{1-\left(\frac{V_{r}}{k U_{r}}\right)^{2}} \\
V_{r}-U_{r} \cos \alpha+\frac{\pi}{6} X_{c} I_{r} \\
G_{11} V_{r}+G_{12} V_{h v}-I_{r} \\
G_{21} V_{r}+G_{22} V_{h v}+\alpha I_{l v} \\
\alpha V_{h v}-V_{l v} \\
H_{11} V_{l v}+H_{12} V_{t}-I_{l v} \\
H_{21} V_{l v}+H_{22} V_{t}-P_{t} V_{t}^{-1}
\end{array}\right]
$$

The Lagrangian formulation is used to solve the optimization issue: $L(z)=f(x, u)+\lambda^{T} g(x, u)+\mu^{T} h(x, u)$. The optimization program has been computed using fmincon Matlab@ function.

For this part, some modifications have been made on the supply system topology. Then, similarly to classical structures, only two DC/DC substations are considered, located on the same position at 500 and 1000 meters from the initial position. The light rail system works at a constant power of $1 \mathrm{MW}$. It is assumed to go from initial to final stations only one time.

Results presented on Fig. 7 shows the global losses calculated on the AC side of TSS. 


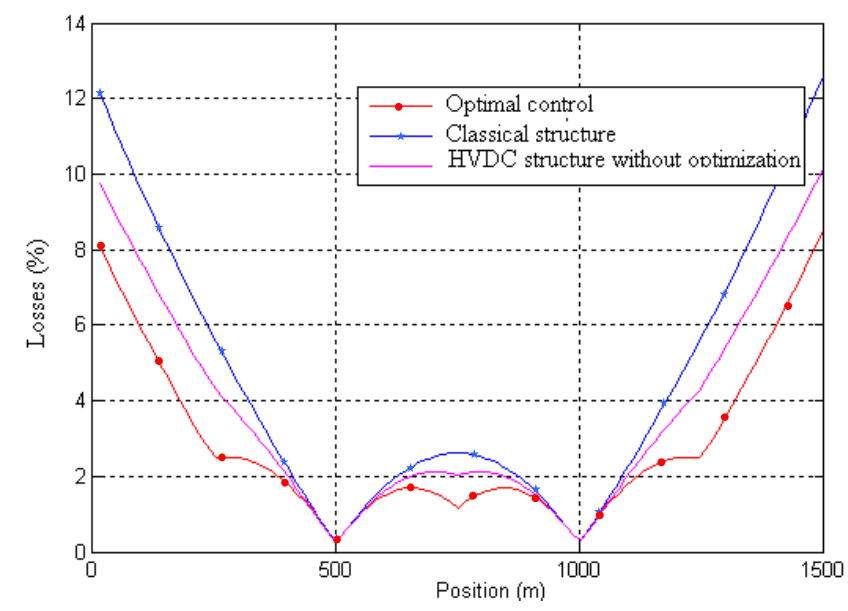

Fig. 7. Global losses of optimal design

Moreover, power quality of supply is also improved as it can be observed on Fig. 8. Therefore, voltage drops are significantly reduced using control strategy from optimization process.

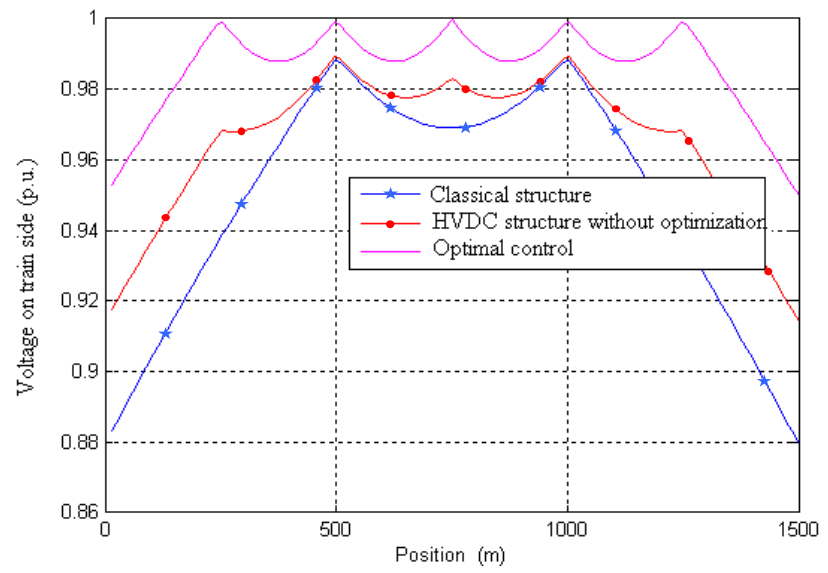

Fig. 8. Voltage on train side of optimal design

It can then be shown that, at each time, control algorithm reaches voltage limits for at least one $\mathrm{DC} / \mathrm{DC}$ converter to allow maximization of efficiency.

\section{CONCLUSION}

A complete simulation tool of a light rail system supplied by original HVDC electrical system is presented in this paper. This tool is particularly useful for designers as they have a global survey of electrical and mechanical variables of the system. Moreover, this tool can be coupled with optimization calculations in order to improve efficiency and performances by modifications on structure or command of substations. Then, it has been shown that optimal control of substations allows the significant improvement of the global efficiency of the studied structure compared to classical power supply systems.

Further works can be conducted in this design subject and it seems to be relevant for the authors to focus on the contribution of control strategy to improve the efficiency of the system and to study stability issues. Then, this simulation tool will integrate dynamic and harmonic models of components.

\section{ACKNOWLEDGMENT}

The authors thank Alstom Transport Company, especially Dr. Daniel Cornic, for its industrial support.

\section{APPENDIX}

The per unit transformation equations for $\mathrm{AC}$ and $\mathrm{DC}$ electrical variables are resumed in this section.

$$
\begin{array}{ll}
S_{a c, \text { base }}=S & P_{d c, \text { base }}=S_{a c, \text { base }} \\
U_{a c, \text { base }}=U & V_{d c, \text { base }}=\frac{3 \sqrt{2}}{\pi} U_{a c, \text { base }} \\
I_{a c, \text { base }}=\frac{S_{a c, \text { base }}}{\sqrt{3} U_{a c, \text { base }}} & I_{d c, \text { base }}=\frac{\pi}{\sqrt{6}} I_{a c, \text { base }} \\
Z_{a c, \text { base }}=\frac{U_{a c, \text { base }}^{2}}{S_{a c, \text { base }}} & Z_{d c, \text { base }}=\frac{18}{\pi^{2}} Z_{a c, \text { base }}
\end{array}
$$

\section{REFERENCES}

[1] Alstom Transport website. Citadis(C) presentation website http://www.transport.alstom.com/home/elibrary/technical/products/320 35.EN.php?languageId $=$ EN\&dir $=/$ home/elibrary/technical/products/

[2] Powerex, RA20, 3600 A, General purpose rectifier. Web site : http://www.pwrx.com/pages/search/search_specasp?catid=30

[3] E. Morin, Modelling of railway electrical network : from component tio system, $\mathrm{PhD}$ thesis of Université Joseph Fourrier, in french.

[4] C.J. Goodman, L.K. Siu, T.K. Ho, "A review of simulation models for railway systems", IET International Conference on Development in Mass Transit systems, 1998, pp.80-85.

[5] N. Flourentzou, V.G Agelidis, G.D. Demetriades, "VSC-HVDC power transmission systems : an overview", IEEE Trans. On Power Electronics, Vol. 24, No.3, pp.592-602, 2009.

[6] R. Vermaack, J.H.J. Potgieter, M.J. Kamper, "Grid-connected VSCHVDC wind farm system and control using permanent magnet induction generators", IEEE International Conference on Power Electronics and Drive, PEDS, 2009.

[7] P. Martin, "Train performance simulations", IET Professional development course on Electric Traction Systems

[8] Y.S. Tzeng, N. Chen, R.N. Wu, "Electric network solutions of DC transit systems with inverting substations", IEEE Trans. On Vehicular Technology, vol. 47, No. 4, November 1998.

[9] Y.S. Tzeng, R.N. Wu, N. Chen, "Unified AC/DC power flow for DC system simulations in DC electrified transit railways", IEE Power Applications, Vol. 142, No. 6, November 1995.

[10] A. Der Vernassian, G. B. Charehpetian, "Decoupled AC/DC load flow for monte carlo simulation of metro power system", Iranian Jouranl of Science \& Technology, Transaction B, Vol. 28, No. B3

[11] R. Barrero, X. Tadoen, J. Van Mierlo, "Quasi-static simulation methods for evaluation of energy consumption in hybrid light rail vehicles", IEEE Vehicle Power and Propulsion Conference, VPPC, 2008.

[12] S. Chenh, M. Sautreuil, D. Riu, N. Retière, "Quasi-static decoupled load flow modelling of a power supply network with AC-DC converters applied to light rail systems", proceedings of the European Conference on Power Electronics and Applications, EPE'2007.

[13] P. Kundur, Power system stability and control, publication of Electric Power Reserach Institute.

[14] D. Gonzàlez, F. Manzanedo, "Optimal Design of a D.C. Railway Power Supply System", IEEE Electrical Power \& Energy Conference, 2008C.S Chang, W. Wang, A.C. Liew and F.S. Wen, "Bicreterion optimization for traction substations in mass rapide transit systems using genetic algorithm", IEEE Proc.-Elect. Power Appl., Vol 145, No. 1, January 1998. 